\title{
RESÍDUOS SÓLIDOS: A MÁ GESTÃO PÚBLICA COMO PROBLEMA AMBIENTAL
}

\author{
Ana Keuly Luz Bezerra ${ }^{1}$ \\ Instituto Federal de Educação, Ciência e Tecnologia do Piauí (IFPI) \\ Paulo Henrique Franco Rocha ${ }^{2}$ \\ Instituto Federal de Educação, Ciência e Tecnologia do Maranhão (IFMA)
}

José Machado Moita Neto ${ }^{3}$

Universidade Federal do Piauí (UFPI)

\section{RESUMO}

A má gestão pública dos resíduos sólidos no Brasil tornou-se um de seus maiores problemas ambientais, resultando em uma atuação que conspira contra o modelo de cidadania instituído pela Carta Constitucional de 1988 e pela inefetividade da política nacional criada para o enfrentamento da questão. Neste estudo, analisou-se a atuação do poder judiciário como instrumento de efetividade da implementação da Política Nacional de Resíduos Sólidos (PNRS) ao pressionar a gestão pública por meio de sanções jurídicas, a tornar-se eficiente, contribuindo para a minimização do problema de gerenciamento de resíduos sólidos no Brasil. Para isso, utilizou-se da análise de conteúdo de dez decisões do Superior Tribunal de Justiça, selecionadas a partir da palavra chave "resíduos sólidos" no site do referido tribunal. Os resultados evidenciaram a dificuldade na implementação da PNRS pelos gestores municipais e a necessidade de revisão da Lei n. 9.605/1998 (Lei de Crimes Ambientais), ajustando-a aos preceitos e diretrizes da PNRS, com o objetivo de instituir subsídios penais que instiguem

1 Doutora e Mestre em Desenvolvimento e Meio Ambiente pela Universidade Federal do Piauí (UFPI). Graduada em Administração pela Universidade Estadual do Maranhão (UEMA) e em Direito pela Faculdade de Imperatriz (FACIMP). Docente do IFPI. Docente colaboradora do Programa de PósGraduação em Desenvolvimento e Meio Ambiente da UFPI. ORCID: http://orcid.org/0000-00026234-2474 / e-mail: analuz@ifpi.edu.br

2 Doutor em Desenvolvimento e Meio Ambiente pela UFPI. Mestre em Administração pela Fundação Instituto Capixaba de Pesquisas em Contabilidade, Economia, Administração e Finanças (FUCAPE). Especialista em Engenharia da Produção pelo Centro Universitário Santo Agostinho (UNIFSA). Bacharel em Administração pela Faculdade do Vale do Itapecuru (FAI). Professor do IFMA. ORCID: http://orcid.org/0000-0002-9421-133X / e-mail: paulo.rocha@ifma.edu.br

3 Doutor e Mestre em Química pela Universidade Estadual de Campinas (UNICAMP). Graduado em Ciências (habilitação em Química), em Engenharia Civil e em Filosofia pela UFPI. Aposentou-se como professor titular da UFPI em 2016, mas continuou pesquisando e orientando teses e dissertações no programa de Pós-graduação em Desenvolvimento e Meio Ambiente como professor voluntário. ORCID: http://orcid.org/0000-0003-3268-1907 / e-mail: jmoita@ufpi.edu.br; jose.machado.moita. neto@gmail.com

Veredas do Direito, Belo Horizonte, ·v.17 ·n.39 · p.39-66 · Setembro/Dezembro de 2020 
a efetividade ambiental de uma administração eficiente ou, como ultima ratio, fortalecer o judiciário em suas intervenções para avalizar um meio ambiente equilibrado para todos, conforme preceitua a Constituição Federal.

Palavras-chave: efetividade; gestão pública; problemas ambientais; resíduos sólidos.

\section{SOLID WASTE: POOR PUBLIC MANAGEMENT AS AN ENVIRONMENTAL PROBLEM}

\section{ABSTRACT}

Poor public management of solid waste, in Brazil, has become one of its greatest environmental problems, resulting in actions that conspire against the citizenship model established by the 1988 Constitutional Charter and the ineffectiveness of the national policy created to address this issue. This study analyzes the performance of the judiciary as an instrument of effectiveness in the implementation of the National Policy of Solid Waste (PNRS) by pushing public management through legal sanctions to become efficient, contributing to minimize the problem of solid waste management in Brazil. For this, we used the content analysis on 10 decisions of the Superior Court of Justice, selected from the keyword "solid waste" in the courts' website. The results showed the difficulty in the implementation of PNRS by municipal managers and the necessity to revise the Law 9.605 / 1998 (Environmental Crimes Law), adjusting it to the PNRS precepts and guidelines, with the purpose of instituting criminal subsidies that instigate the environmental effectiveness of an efficient administration or, as an last resource, strengthen the judiciary in its interventions to support a balanced environment for all, as required by the Federal Constitution.

Keywords: effectiveness; environmental problems; public management; solid waste. 


\section{INTRODUÇÃO}

A Política Nacional de Resíduos Sólidos (PNRS), Lei n. 12.305/2010 ingressou no ordenamento jurídico ambiental brasileiro, para instituir, de maneira escalonada, responsabilidades para garantir a proteção ambiental, por meio do gerenciamento integrado dos resíduos sólidos. No entanto, embora se constitua como uma prioridade da política pública ambiental brasileira, o gerenciamento atual dos resíduos sólidos é desordenado e incompatível com a economia, com as dimensões e com as potencialidades do Brasil. Diante disso, é possível perceber que as insuficiências e desconformidades dos dados do panorama de resíduos sólidos no Brasil demonstram a falta de efetividade da PNRS e incitam a necessidade de sua procedimentalização. A Carta Constitucional do Brasil, ao estabelecer os princípios da Administração Pública, pressupõe o direito imprescindível da população à gestão pública eficiente, que deve ser pautada na governança adequada, embasada em condutas éticas, na transparência e no envolvimento da população nas decisões. Desse modo, ao permitir a discricionariedade ao gestor público, a Constituição brasileira atribui a este a função de sempre encontrar a melhor solução. Havendo tal escolha, toda a estrutura administrativa precisa estar a ela vinculada, assumindo, portanto, a obrigação de implementá-la. Assim, no processo de tomada de decisões, o gestor público deve habitualmente ponderar a utilidade e a conveniência entre as opções existentes, fazendo a opção por aquela que melhor atenda ao interesse social, sob pena de sofrer o controle pelos outros poderes, estabelecido em lei pelo sistema de "freios e contrapesos"4.

Essas prescrições reconhecem a liberdade discricionária na administração pública que, obviamente, não está imune à inquirição jurídica, uma vez que o Estado brasileiro está estruturado na interdependência entres os poderes, cabendo ao Judiciário assegurar a integridade da administração pública ao atuar no controle das ações dos agentes públicos. Assim, o presente estudo tem como objetivo examinar a atuação do poder judiciário como instrumento de efetividade da implementação da Política Nacional de Resíduos Sólidos (PNRS) ao pressionar a gestão pública por meio de sanções jurídicas, a tornar-se eficiente, contribuindo para a minimização do problema de gerenciamento de resíduos sólidos no Brasil.

4 Princípio constitucional incorporado no sistema jurídico para melhoria do funcionamento do Estado, sistematizado pelo equilíbrio necessário para a promoção isonômica de acesso dos cidadãos aos direitos fundamentais, como saúde, educação, transporte, moradia e desenvolvimento, sendo, desse modo, fundamental para a garantia jurídica da efetividade das políticas públicas (VELOSO, 2018). 
Para esse propósito, realizou-se revisão bibliográfica e pesquisa documental para coleta de dados. Para avaliação crítica dos dados, optou-se pela análise de conteúdo, que se constitui no estudo qualitativo de fatos. A partir da revisão bibliográfica, observou-se a perspectiva histórica da administração pública no Brasil, com o intuito de ponderar os entraves e dilemas que permeiam a gestão contemporânea e reconhecer que os elementos basilares necessários para um gerenciamento ideal estão explícitos nos princípios constitucionais da administração pública. Da pesquisa documental resultaram dez decisões do STJ, alicerce necessário para demonstrar como os princípios constitucionais da administração pública mencionados são interpretados. Por fim, as amostras de validação jurisdicional do STJ foram apresentadas como fatores de amparo a uma gestão pública eficiente.

\section{MÉTODOS E PROCEDIMENTOS}

A pesquisa documental foi constituída pela busca de processos julgados pelo STJ, realizada no campo Jurisprudência, pesquisa livre, em que se utilizou a expressão "Resíduos Sólidos". A consulta resultou em 47 acórdãos, 1.184 decisões monocráticas e 2 informativos de jurisprudências. As decisões monocráticas e informativos de jurisprudências foram excluídos do universo, posto que o objetivo era analisar decisões coletivas para observar possíveis divergências entre os julgadores, totalizando 47 documentos o corpus do estudo.

Os critérios de seleção dos processos utilizados para análise foram: (a) obtenção, por meio de consulta ao site do STJ, das ações com as características anteriormente mencionadas e julgadas com análise de mérito no período compreendido pelos últimos 5 anos (período de exigibilidade do cumprimento da PNRS); (b) numeração sequenciada das ações encontradas e seleção, a partir da utilização de um app de escolha aleatória e de acesso livre, a fim de se manter a imparcialidade na escolha dos textos; e (c) definição da amostra do estudo, a qual resultou em três acórdãos e sete decisões monocráticas.

Delimitado o corpus do estudo e as amostras da pesquisa documental, utilizou-se da análise de conteúdo de Bardin (2009), que possibilitou a identificação das noções elementares relacionadas a cada matéria abordada e, desse modo, foi possível identificar as decisões mais adequadas para contextualizar as discussões apresentadas. 


\section{BREVE HISTÓRICO A CAMINHO DA GESTÃO PÚBLICA EFICIENTE}

A administração pública no Brasil foi estruturada por um estado absolutista, pautada em critérios de pessoalidade, parentelismo e peculato, valores instituídos ainda no período da colonização, quando as autoridades políticas governavam numa condição soberana e de indistinção entre bens públicos e privados. Conhecido como patrimonialismo, esse modelo de gestão, iniciado no Brasil Colônia (1500-1822), prevaleceu durante o Império (1822-1889) e, também, no estágio inicial da República (1889-1930) (COSTA; COSTA, 2016), momento que, mesmo pautado em ideais democráticos, foi dominado pelo Coronelismo (COMPARATO, 2018).

A história revela que o Coronelismo institucional se estabeleceu no Brasil mediante a compra de títulos militares pelos abastados latifundiários. Desse modo, os "Coronéis", que detinham o poder econômico no país, consolidaram sua hegemonia com inquestionável poder político e social. No entanto, com as mudanças no capitalismo global, afetando as commodities tradicionais e estimulando a industrialização, eles perderam sua força econômica, mas mantiveram sua influência política, situação que afetou a visão representativa do Estado e conduziu a administração pública a uma proposta de burocratização. Contudo, uma crise administrativa se acumulou no país da Era Vargas (1930-1945) até a República Populista (1954-1964), reduzindo o modelo burocrático a uma condição monopolista e ineficaz, o que potencializou o clientelismo e o corporativismo, resultando em vícios de mau uso das verbas públicas.

A administração burocrática, mesmo guarnecida por fundamentos norteadores de defesa racional do patrimônio público, em função de sua condição inflexível, tornou a Administração Pública pouco eficiente (RIBEIRO FILHO; VALADARES, 2017). Desse modo, o Governo Militar (1964-1985), no intuito de superar os desgastes do modelo burocrático vigente e estimular a evolução econômica, sanciona o Decreto Lei n. 200/67 que estatui normas para a reestruturação da administração federal (ROMÃO NETTO, 2016).

O formato burocrático, proposto pela regência militar, tentou implementar no Brasil um modelo de gestão sistematizado pela administração indireta, denominado de gerencialismo, o que propiciou a admissão de servidores sem certame público e, assim, potencializou a práxis patrimonialista e enfraqueceu o padrão de gerência pública burocrática (PEREIRA, 
1998). Desse modo, incitado pelas dinâmicas que conduziram à democratização política do Brasil (1985), o modelo burocrático cedeu lugar à administração gerencial. Tal formato de gestão se aperfeiçoou "na abundância de normas, buscando assegurar a garantia de direitos dos cidadãos e limitar a amplitude de poderes do Estado, resultando na mais administrativa de todas as Constituições brasileiras" (BRULON; OHAYON; ROSENBERG, 2012, p. 270).Sancionada no ano de 1988, a Constituição instituiu a legalidade, a impessoalidade, a moralidade, a publicidade e a eficiência, como princípios essenciais para a gestão pública.

A atual Constituição Federativa do Brasil (CF/88) traz aspectos singulares da relação público-privada ao consolidar, nos arts. 37 a 43, direcionamentos para a administração pública. Desse modo, todas as pessoas vinculadas, direta ou indiretamente, à gestão pública no Brasil, em qualquer poder, seja do Distrito Federal, Estados, Municípios ou União, têm o dever de acatar os preceitos ideológicos ali prescritos.

O Estado, ao reconhecer a insuficiência do mercado em colocar em equilíbrio, de modo singular, desenvolvimento econômico e sustentável, optou por uma administração gerencial, que, apesar de ainda se mostrar rudimentar no país, é caracterizada pela interferência do governo, como agente regulador, para o estabelecimento de meios destinados a resguardar os interesses públicos (PEREIRA, 2014).

A administração pública no Estado contemporâneo brasileiro, de acordo com Bitencourt Neto (2017), apresenta um conjunto de visões administrativas sintetizadas como infraestrutural, procedimentalizada, multipolar, em rede e concertada, que, embora não sejam mutuamente exclusivas, são úteis para identificar algumas características que aparecem nos vários estilos de administrar, antes que a administração se transforme completamente em eficiente, o que corresponderia ao fim último de uma administração moderna.

Sendo assim, a administração infraestrutural se distingue por não se prender a execução direta, mas pela garantia de aparelhagens e meios para o fornecimento de serviços básicos; a procedimentalizada está pautada na atuação racional e produtiva, materializada na participação pública; a multipolar torna os efeitos das decisões estendidos à coletividade; a gestão em rede é modelada pela formação de conexões num processo de atuação coordenada para troca ou compartilhamento de informações ou recursos; a concertada incorpora várias tarefas administrativas internas às relações administrativas externas, e, por fim, a gestão eficiente tem como meta mudar 
o padrão da administração pública, a começar por um processo de privatizações e uso de instrumentos de gestão privada.

Não obstante, Martins (2018) explica que a globalização no século XXI motivou a uniformização das perspectivas de futuro, possibilitando uma relação de intenso fluxo entre as sociedades desenvolvidas e em desenvolvimento, impelindo o Estado, como instituição, a se adaptar, por meio da concepção de administração correlacionada a soluções, mesmo que em seu cerne os contrates nos aspectos econômico e de bem-estar social permaneçam. Nesse cenário, a Administração Pública moderna tem como escopo a versatilidade e, de acordo com Almeida, Scatena e Luz (2017), é instigada a ultrapassar o discurso abstrato e materializar as metas por meio de programas racionais.

Para a modernização da Administração Pública, tornou-se indispensável a avaliação de políticas públicas a fim de aprimorar, tanto do planejamento quanto da gestão, mudança que resultou em alterações na relação entre o Estado e a Sociedade e direcionou para a aplicação de fundamentos da gestão pública empreendedora (CUNHA, 2018). O governo empreendedor, segundo Secchi (2009), tem sua base estrutural na administração pública gerencial. O autor destaca que esse modelo se assemelha ao Burocrático no aspecto de controle e na concepção de distinção entre política e administração pública. No entanto, no modelo gerencial a responsabilidade quanto aos resultados das políticas públicas repercute na atuação política dos gestores e pode ser amenizada com a adoção de decisões compartilhadas, respaldadas no envolvimento da comunidade nas decisões. O explicitado coloca em evidência que, embora a conjuntura sistêmica postule mecanismos inovadores, compreender e fomentar condutas de sustentabilidade é um desafio para as nações.

\section{A GESTÃO PÚBLICA DOS RESÍDUOS SÓLIDOS NO BRASIL}

No Brasil contemporâneo, a gestão pública é permeada por elementos híbridos de gestão, desse modo, indícios patrimonialistas resistem. Apesar disso, os padrões predominantes, burocrático e gerencial convivem em harmonia, mas não conseguem atender plenamente aos preceitos da Norma, sobretudo no que concerne aos resíduos sólidos, pois, enquanto a gestão burocrática tende a gerar morosidade nos processos de licenciamento e fiscalização, a gerencial não dispõe de parâmetros e/ou indicadores para 
tratar essa questão dentro de critérios reais e transparentes. Desse modo, o contexto contemporâneo determina que, para ser sustentável, a administração pública deve estar preparada para amparar a gestão política em qualquer situação, seja em momentos estáveis ou turbulentos (ŽURGA, 2017). Nesse cenário, Martins (2018) afirma que o novo padrão se volta para a sustentabilidade, com foco no desenvolvimento das pessoas e no respeito ao meio ambiente, o que demanda direcionamentos por meio de políticas públicas.

No momento em que o direcionamento predetermina políticas públicas ambientais, as premissas de conscientização propõem elos de comprometimento intergeracional e, em vista disso, sugerem tornar possível um meio ambiente mais adequado para as gerações futuras. Esse entendimento simboliza a parte fundamental da relação do homem e do mercado com a natureza, uma vez que proteger o meio ambiente tem relação com a continuidade da vida, sendo, desse modo, um assunto de interesse global, que requer compromissos firmados pelas nações que integram a sociedade internacional, e constituem, portanto, uma das metas centrais da Organização das Nações Unidas (ONU), que se materializa por meio de debates, especialmente, quando abordam os impasses entre o desenvolvimento e proteção ambiental.

Na década de 1970, os diálogos na ONU versaram sobre proposições voltadas à preservação ambiental e buscavam a formulação de procedimentos globais. Em vista disso, a conferência realizada em 1972 na capital da Suécia, Estocolmo, foi destacada como uma referência para o direito ambiental, uma vez que as autoridades reunidas outorgaram regulamentos estratégicos a respeito da relação homem e meio ambiente (JAPIASSÚ; GUERRA, 2017).

Nesse período, segundo Câmara (2013, p. 131), o Brasil procurava fortalecer a industrialização, o que resultou no encaminhamento de "maior engajamento da sociedade nos temas ambientais e sociais, notadamente com relação às consequências desastrosas verificadas com a poluição industrial e a contaminação de áreas urbanas próximas, que resultaram em problemas graves de saúde das populações afetadas". Em sintonia, Japiassú e Guerra (2017) afirmam que o país participou e assinou o Tratado de Estocolmo, contudo não o executou conforme as regras, tendo em vista que vivia sobre a regência militar, com fito centrado numa política desenvolvimentista obstinada pelo desenvolvimento econômico. 
A ONU retomou as discussões sobre Meio Ambiente e Desenvolvimento vinte anos após a conferência realizada em Estocolmo. Assim, em 1992, transcorreu no Rio de Janeiro, Brasil, a Rio 92, que, além de confirmar os preceitos pactuados na Suécia, inseriu um novo conceito relacionado a uma condição futura, no qual recomenda que, equivalente a produzir e consumir, deve-se incluir o cuidado com os recursos por meio da reciclagem. No final, todas as deliberações foram materializadas num manuscrito alcunhado de Declaração do Rio de Janeiro (ONU, 1992). Um novo documento, composto por metas para a agenda 21 , propondo objetivos direcionados a combinar prosperidade econômica, justiça social e preservação ambiental, foi assinado pelos países membros da ONU, na conferência sobre desenvolvimento sustentável intitulada de Rio +10 , realizada em 2002 na capital da África do Sul, Joanesburgo.

Nesse meio tempo, as convenções internacionais sobre meio ambiente incitaram novas posturas gerenciais e conceituais, a começar pelo Decreto Lei n. 73.030/1973, que deu origem a Secretaria Especial do Meio Ambiente (SEMA), uma instituição autônoma de administração direta voltada para a preservação do meio ambiente e aplicação responsável dos recursos naturais. Mas a singularidade na legislatura pode ser mais bem percebida na década de 1980, pela Lei n. 6.803/1980, que trata das normas básicas para o zoneamento industrial, impondo para instalação de uma indústria a avaliação ambiental preliminar.

No ano seguinte, a Lei n. 6.938/1981 criou a Política Nacional do Meio Ambiente, na qual foi especificado a harmonização entre crescimento econômico e proteção ambiental, bem como dispositivos de proteção relativos à prevenção, além de prenunciar meios de repressão e compensação de danos.

Em 1988, a matriz constitucional do Brasil, de modo inédito, infere à proteção ambiental em vários de seus preceitos, sedimentados por um capítulo reservado à temática ambiental, no qual está inserido o art. 225 cujo caput prescreve que "[t]odos têm direito ao meio ambiente ecologicamente equilibrado, bem de uso comum do povo e essencial à sadia qualidade de vida, impondo-se ao poder público e à coletividade o dever de defendê-lo e preservá-lo para as presentes e futuras gerações" (BRASIL, 1988).

Como meio de atendimento à Carta Magna, a Lei n. 7.802/1989 decretou sobre o procedimentos e destinação final de resíduos e embalagens relacionados a agrotóxicos, seus componentes e afins; ao mesmo tempo, transcorreu no Senado Federal a proposta de Lei n. 354, que preceitua responsabilidades quanto ao direcionamento final dos resíduos gerados pelos 
sistemas de saúde no que compete ao acondicionamento, recolhimento, tratamento, movimentação e destinação. Difusão que, segundo Faria (2012), deu início a debates que fomentaram o gerenciamento de resíduos sólidos ordenados por legislação nacional, uma vez que, de acordo com Nascimento Neto e Monteiro (2010), a normatização sobre resíduos sólidos urbanos (RSU), no Brasil, estava fragmentada em inúmeras portarias, resoluções, decretos e leis.

A PNRS, regulamentada pelos Decretos n. 7.404/2010 e 7.405/2010 e instituída pela Lei n. 12.305/2010, surge como dispositivo de alinhamento entre União, Estados e municípios, com direcionamentos para disposição adequada de rejeitos distribuídos em 57 artigos voltados a tornar compreensível a importância das demandas alusivas aos resíduos e rejeitos. Nesse panorama, a PNRS tem como premissa o compromisso compartilhado pelo ciclo de vida dos produtos e, desse modo, traz, em seu texto, direcionamentos de gestão ao estabelecer, entre seus instrumentos, os planos de resíduos em escalas hierárquicas, uma vez que reconhece a liberdade administrativa constitucional dos municípios e o poder discricionário da administração pública.

\section{BOA GESTÃO À MARTELADA - O JUDICIÁRIO INDUZINDO A GESTÃO PÚBLICA EFICIENTE}

Quando se considera que a finalidade básica da ação de governar reside na responsabilidade pelo bem-estar da população, fica mais fácil compreender as especificidades de uma política pública, sobretudo quando essa intervenção se expressa em lei, o que estimula a construção de planos e programas que tornam mais claro o entendimento do que se pretende alcançar (LUNAS; OLIVEIRA; BONONI, 2016).

Embora tenha se direcionado para esse fim, a Administração Pública brasileira, segundo Maiello, Britto e Valle (2018), tem encontrado obstáculos para a sistematização de políticas, uma vez que existe um distanciamento material e estrutural entre os poderes formuladores e executores, que se torna evidente pelas dificuldades de gerenciamento e de entendimento dos procedimentos de execução, seja na esfera municipal, lugar em que as políticas são materializadas, seja no âmbito regional, onde tem muita importância a coexistência de diferentes políticas. Segundo Corralo (2017), quando uma administração pública trabalha em harmonia com os princípios constitucionais materializa a boa administração. Contudo, para 
entendimento da boa administração em um estado federativo como o Brasil, constituído de diversidades regionais ou locais, é compulsória a compreensão particularizada em cada esfera de governo (CORRALO, 2014).

O poder judiciário, de acordo com Grinover (2010), está constitucionalmente conectado com as políticas públicas e, para obtenção das finalidades elementares do Estado, deve observar os limites postos à sua intervenção, buscar harmonia e respeitar a independência dos demais poderes. Feito isso, pode proceder na implementação de políticas públicas ou na correção delas, sempre que constatar imprecisão.

Da Constituição Federal emanam direitos fundamentais que pressionam a aplicabilidade dos deveres constitucionais da administração pública. Desse modo, tais imposições convergem para uma subordinação jurídica, em que as ações da gestão pública, embora acatem os procedimentos protocolares prescritos, podem ter sua legalidade investigada em razão de ofensa aos princípios da administração Pública (HACHEM, 2013). Para Pessoa, Cardoso e Sousa (2015, p. 129),

[...] pode-se afirmar que políticas públicas que versem acerca dos direitos sociais fundamentais a moradia, saúde, educação e segurança pública merecem contar com elevado grau de proteção judicial. Quando algo vai mal - total omissão ou mau funcionamento da prestação estatal por parte do Executivo, a porta a bater que resta ao cidadão é a do Poder Judiciário.

Para garantia dos direitos básicos, o Poder Judiciário intervém junto a outras instâncias por meio de orientações e/ou imposições, seja ao Poder Executivo para efetivação de ações, ou seja, diretamente ao gestor público que não se dedicar a seu dever (KOHLS; LEAL, 2015). O STJ ratifica o exposto ao tornar público que

[...] a negligência na condução da máquina pública evidencia ato de improbidade e não mera irregularidade. À luz dos princípios constitucionais da legalidade, moralidade $\mathrm{e}$ eficiência, corolários de um princípio mais amplo, o da "boa administração", não há espaço para o gestor "desatento" ou "despreparado" (BRASIL, 2017).

A CF/88, segundo Teixeira (2012), atribui ao Poder Judiciário aproximação com a sociedade, o que, de certo modo, incita midiatização em suas ações, fato que alcança o STF no que tange à legitimação de políticas públicas e projetos sociais que, por sua vez, conseguem na legislação instrumentos orgânicos para sua efetivação.

Segundo Ohlweiler (2013), os princípios constitucionais da Administração Pública não se processam apenas no significado das 
palavras, mas na relação entre o exame dos escritos e a herança cultural. Levando em conta essa afirmação, apresenta-se, apoiado nas decisões do STJ, o entendimento do Tribunal sobre os princípios constitucionais da administração pública, visando a eficiência da administração.

Consta no REsp 1199572 MG 2010/0118523-3 (BRASIL, 2010d), julgado em 02/09/2010 e relatado pelo Ministro Castro Meira, que o município de Farroupilha (RS), em conjunto com outros servidores públicos municipais, cometeu ação de improbidade administrativa, com prejuízo às finanças públicas, na contratação de empresa para prestação de serviços na limpeza de vias públicas, coleta, destinação e tratamento dos resíduos sólidos.

Conforme foi extraído do julgado, o Edital do certame apoiou-se no padrão licitatório de técnica e de preço, padrão este que se destina apenas para licitação de caráter predominantemente intelectual e que, indiscutivelmente, pode ser utilizada na contratação de serviços públicos. Contudo, pelo que foi apurado no litígio, o regime almejado pelo poder público municipal farroupilhense se configura como concessão de serviço público. Nessa perspectiva, ao mesclar as duas modalidades de prestação de serviços no édito, contratação e concessão, houve uma afronta ao princípio constitucional da legalidade que, na opinião de Pereira (2014), é expressa quando o administrador age dentro dos limites da legislação, portanto, juridicamente, estipula a inexistência de crime para fatos não prenunciados em lei. Em vista disso, a legalidade pode ser entendida como um escudo de proteção expresso pelas regras de conduta.

O Edital supramencionado, sem apresentar fundamentos, não permitiu que empresas consorciadas integrassem a disputa. Por isso, na perspectiva do STJ, além de afronta ao art. 33 da Lei n. 8.666/93, que regulamenta os deveres das empresas consorciadas na participação em licitações, ocorreu desvio do desígnio de eleger a proposição mais favorável para a administração pública, o que sugere lesão, tanto à impessoalidade, quanto à moralidade administrativa. A impessoalidade, na operação do processo administrativo, relaciona-se com a conduta do servidor público. Assim, no desempenho de sua função ele deve ter o compromisso moral de, em nenhuma circunstância, pautar suas decisões apoiadas em um prisma pessoal que torne possível o nepotismo, favorecimentos ou relações de amizade. A moralidade, por sua vez, enquanto diretiva de gestão, é mencionada na carta constitucional como uma condição de atuação do agente público, presumindo que, no exercício da função, sua atitude 
deve ser pautada, sempre, na identificação, distinção e acatamento aos parâmetros da ética, honestidade e integridade de caráter, pois, conforme destaca Freitas (2008), tal princípio reconhece a importância das condutas, em que a questão central reside em conhecer os limites.

O princípio da publicidade direciona-se para a maneira como os gestores públicos devem processar a comunicação na administração pública, por isso, tal princípio recomenda que a divulgação não deva transcorrer apenas "como um sistema fechado de transparência ou repasse de informações públicas, mas como uma maneira de empoderar a sociedade civil e os diferentes atores envolvidos" (CEZAR, 2018, p. 54-55). Com esse viés, o STJ analisou o AREsp 290114 MG 2013/0022746-5, relatado pelo Ministro Mauro Campbell Marques e julgado em 31/05/2013, no qual o Clube Atlético Mineiro reclamou contra o Município de Belo Horizonte, alegando ausência de notificação prévia ao contribuinte da cobrança anual do IPTU e da Taxa de Coleta de Resíduos Sólidos, alegando, ainda, que é dever do município comprovar que o contributário recebeu efetivamente a guia de cobrança.

$\mathrm{Na}$ apreciação da situação, o Fórum de origem reconheceu que a remessa das guias de cobrança, via correio, possa ser considerada uma notificação. O referido órgão deixou claro que o IPTU e as taxas que acompanham a guisa são conhecidamente tributos devidos e esperados, logo, havendo atraso ou não no recebimento do impresso de recolhimento, o contribuidor pode reclamar nos postos de atendimento da prefeitura ou obter uma segunda via pela internet. O Fórum concluiu que, apesar disso, a cada final de ano a municipalidade deve dar ampla publicidade das datas de vencimento, dos valores e das possibilidades de pagamento com desconto. A Corte superior ratificou o parecer supracitado negando provimento ao agravo.

A eficiência foi aditada aos princípios constitucionais da administração pública por meio da Emenda Constitucional n. 19/1998, e advém como condição fundamental no governo ao relacionar produtividade com o uso dos recursos e instigar a qualidade e competência dos servidores. Assim, uma gestão eficiente traduz-se na "necessidade de reduzir custos e aumentar a qualidade dos serviços, tendo o cidadão como beneficiário" (GICO JUNIOR, 2018, p. 110). Desse modo, ao relatar a SS 3.093 AL 2019/0145309-6, julgada em 30/05/2019, o Ministro Presidente do STJ, João Otávio de Noronha, discorreu sobre o recurso impetrado pelo município de Maceió contra o Tribunal de Justiça de Alagoas (TJAL), 
requerendo suspensão dos efeitos de decisão liminar do Juiz convocado do TJAL que ordenou a continuidade dos serviços pela Viva Ambiental até que o respectivo e obrigatório expediente licitatório seja finalizado. A Empresa Viva Ambiental e Serviços S/A, contratada em caráter emergencial pelo citado município para os serviços de limpeza pública urbana, impetrou mandado de segurança com pedido de liminar, solicitando a suspensão de processo de dispensa de licitação para contratação de outra empresa para limpeza pública da localidade até que o certame para a prestação dos serviços seja finalizado. Na origem, o juiz indeferiu a liminar, o que motivou a interessada a interpor agravo de instrumento com tutela de urgência, concedido pelo relator no TJAL.

Ao indeferir o pedido de suspensão, a decisão do STJ anuiu-se com a decisão liminar do TJAL que entendeu não se tratar de situação emergencial, mas ausência de planejamento, uma vez que, após a dispensa de licitação por urgência na Contratação da Viva Ambiental, a administração pública municipal teve 06 (seis) meses para novo procedimento, por isso considerou se tratar de leniência administrativa com ofensa ao princípio basilar da eficiência administrativa.

O direito administrativo, em sua lógica e constitucionalidade, funciona como fonte de transparência, coerência e racionalidade, cuja atribuição decisiva compete aos princípios fundamentais, aos quais é permitido apontar aqueles que são amparados de maior coerência, encaixando-se, nessa circunstância, o princípio da boa administração (CORREIA, 2016). O desempenho de um governo pode ser considerada boa administração quando, "através de políticas públicas e serviços públicos, consegue efetivar os direitos fundamentais consagrados constitucionalmente" (KOHLS; LEAL, 2015, p. 190).

Na legislação brasileira, quando o assunto é a vinculação homem e natureza, a Lei n. 6.938/81, em seu art. $3^{\circ}$, define meio ambiente, degradação e poluição ambiental e a CF/88 destina um capítulo (art. 225) para a temática ambiental, em que, no $\S 1^{\circ}$, é firmado os deveres do poder público para efetividade do direito fundamental ao equilíbrio ambiental.

O gestor público, no Brasil, portanto, para assegurar uma boa administração, tem suporte legal como alicerce para seus propósitos de governo, a exemplo da Lei n. 10.257/2001, que regulamenta os arts. 182 e 183 da $\mathrm{CF} / 88$, ao prescrever no art. $2^{\circ}$ direcionamentos para a política urbana, entre os quais está a "garantia do direito a cidades sustentáveis, entendido como o direito à terra urbana, à moradia, ao saneamento 
ambiental, à infraestrutura urbana, ao transporte e aos serviços públicos, ao trabalho e ao lazer, para as presentes e futuras gerações". De modo consequente, o art. $4^{\circ}$ do Estatuto das Cidades determina entre seus instrumentos os "planos nacionais, regionais e estaduais de ordenação do território e de desenvolvimento econômico e social", os quais se relacionam com os objetivos fixados no art. $7^{\circ}$ da Lei n. 12.305/2010.

Por outro lado, a Lei n. 9.605/1998, que dispõe sobre crimes ambientais, embora consista em penalizar as condutas de lesão ambiental, não traz subsídios para a atuação do judiciário no que se refere às questões específicas da problemática dos resíduos sólidos. Para Oliveira (2017), no momento em que a inquirição judicial não adota parâmetros precisos, torna-se suscetível a preceitos abstratos. Em vista disso, quando se analisa a jurisprudência no STJ sobre a temática ambiental, percebe-se, em grande parte dos julgados, limitações que conduzem ao reconhecimento de que "não há óbice a que aspectos do mérito da causa sejam apreciados, pelo Tribunal a quo, no âmbito do juízo de admissibilidade do Recurso Especial" (BRASIL, 2015).

Em contrapartida, ao julgar a falta de ação de um município na aplicação das disposições indispensáveis para a gestão de resíduos sólidos, o tribunal entendeu que, "diante da omissão e inadequação das medidas adotadas, a tutela jurisdicional pretendida pelo Ministério Público com a condenação nas obrigações de fazer se traduz como meio necessário a assegurar a efetiva adequação às disposições contidas na Política Nacional de Resíduos Sólidos" (BRASIL, 2018b). Para esse caso, o STJ avaliou, também, a obrigação do município referente à organização e ao funcionamento de cooperativas de catadores e decidiu "por afastar algumas obrigações de fazer dirigidas à municipalidade, sob pena de o Judiciário se imiscuir na discricionariedade administrativa" (BRASIL, 2018b).

Por outro lado, a PNRS responsabiliza, além dos fabricantes, os comerciantes, distribuidores e/ou importadores pelo ciclo de vida dos produtos, mesmo que o descarte incorreto tenha sido realizado pelo consumidor final. Desse modo, impõe a logística reversa como um elemento consubstanciado ao processo de produção. No entanto, a Corte, ao julgar recurso de uma indústria de lâmpadas em processo imposto pelo Ministério Público do Estado do Paraná não reconheceu o agravo, mas presumiu, com base no argumento do tribunal de origem, que o município também deve se mobilizar para esse ato, por isso assevera, em síntese, que, 
[...] ao que parece, o v. acórdão se olvidou de que os Municípios também são responsáveis pela coleta de resíduos sólidos e por dar a correta destinação a esse material, motivo pelo qual, verificando-se a negligência do Município em relação ao descarte das lâmpadas, deveria ter reconhecido, no mínimo, a ocorrência de litisconsórcio passivo necessário, e não de litisconsórcio ativo. Trata-se do princípio da responsabilidade compartilhada (BRASIL, 2016).

No caso supracitado, o posicionamento do tribunal de origem, com relação à responsabilidade compartilhada, vai de encontro ao que determina o art. $33^{\circ}$ da Lei 12.305/2010, no qual está convencionado que

[...] são obrigados a estruturar e implementar sistemas de logística reversa, mediante retorno dos produtos após o uso pelo consumidor, de forma independente do serviço público de limpeza urbana e de manejo dos resíduos sólidos, os fabricantes, importadores, distribuidores e comerciantes de: I - agrotóxicos, seus resíduos e embalagens, assim como outros produtos cuja embalagem, após o uso, constitua resíduo perigoso, observadas as regras de gerenciamento de resíduos perigosos previstas em lei ou regulamento, em normas estabelecidas pelos órgãos do Sisnama, do SNVS e do Suasa, ou em normas técnicas; II - pilhas e baterias; III - pneus; IV - óleos lubrificantes, seus resíduos e embalagens; V - lâmpadas fluorescentes, de vapor de sódio e mercúrio e de luz mista; VI - produtos eletroeletrônicos e seus componentes (BRASIL, 2010c, grifo nosso).

Sob outra perspectiva, o gestor público municipal deve assumir posição primária para atendimento aos preceitos da PNRS, uma vez que é seu dever garantir os direitos fundamentais da população, podendo, para tanto, embasar-se no uso de instrumentos da gestão privada para fiscalizar e pressionar os fabricantes, importadores, distribuidores, comerciantes e consumidores ao acatamento da Lei n. 12.305/2010. Para uma atuação efetiva no cumprimento da PNRS, a gestão pública deve respeitar, essencialmente, seu art. $9^{\circ}$, no qual está determinado que "[n]a gestão e gerenciamento de resíduos sólidos, deve ser observada a seguinte ordem de prioridade: não geração, redução, reutilização, reciclagem, tratamento dos resíduos sólidos e disposição final ambientalmente adequada dos rejeitos".

Assim, a Educação ambiental, a reutilização, a reciclagem, o tratamento dos resíduos e a disposição adequada dos rejeitos devem compor o Plano Municipal de Gestão Integrada de Resíduos Sólidos que, além de ser um compromisso obrigatório, de acordo com a PNRS, é requisito prévio para aquisição de recursos da União destinados a gestão de resíduos e compõem o conjunto de obrigações de fazer do gestor municipal.

A não geração e, consequentemente, a redução dos resíduos pode ser resultado da educação ambiental que, além de ser dos instrumentos da Lei 
n. 12.305/2010, tem relação direta com a mudança de cultura. Portanto, instruir a população para uma conduta ambiental adequada é uma atribuição do município, validada nas decisões do STJ, quando direcionadas às medidas necessárias para a gestão integrada de resíduos, em que é proferido que as

[...] obrigações de fazer que devem guardar relação com a realidade econômicofinanceiro do Município, a fim de viabilizar a implementação das medidas necessárias à gestão integrada de resíduos sólidos. Elaboração de Plano Integrado de Gerenciamento de Resíduos da Construção Civil e cadastro de todos os geradores que estão sujeitos à elaboração de Plano de Gerenciamento de Resíduos Sólidos que deve ser concluída no prazo de 18 meses. Obrigações de implantar programa de coleta seletiva, organizar o funcionamento da associação de catadores, estabelecer programa de compostagem, estabelecer programa de educação ambiental que devem ser concluídos no prazo de 12 meses (BRASIL, 2018b).

As ações de coleta de resíduos e rejeitos são asseguradas pela legislação como um serviço que o município pode terceirizar, no entanto, cabe à gestão municipal atenção quanto aos aspectos ético-legais dessa relação, tendo em vista que, na compreensão da Ministra Assusete Magalhães, ao avaliar o AgInt no AREsp 1190179/SP sobre a indevida celebração de aditivos ao contrato de coleta,

[...] a improbidade é ilegalidade tipificada e qualificada pelo elemento subjetivo da conduta do agente. Por isso mesmo, a jurisprudência do STJ considera indispensável, para a caracterização de improbidade, que a conduta do agente seja dolosa, para a tipificação das condutas descritas nos artigos $9^{\circ}$ e 11 da Lei 8.429/92, ou pelo menos eivada de culpa grave, nas do artigo 10 (BRASIL, 2018a).

É, ainda, legalizado pela norma infraconstitucional a cobrança de taxa de coleta pelos municípios, com o propósito de que os valores obtidos sejam convertidos em ações de suporte ao atendimento da PNRS. Para essas situações, o STJ analisou o processo AgRg no REsp 1115373 / PR AGRAVO REGIMENTAL NO RECURSO ESPECIAL 2009/0003763-5, documentos que tratou da inseparabilidade e individualidade das taxas de iluminação e limpeza pública, assim, "a Segunda Turma inaugura jurisprudência que afirma a ilegalidade da cobrança da taxa de coleta de lixo domiciliar, por não atender aos requisitos da especificidade e da divisibilidade. Precedente: AgRg no Ag 1.079.392/SP, Rel. Ministra Eliana Calmon, Segunda Turma, julgado em 17.2.2009, DJe 17.3.2009”.

Os gestores públicos, que não praticam a eficiência na administração, querem fugir da responsabilidade por não implementarem as diretrizes da 
PNRS, usando o argumento de falta de recursos para os municípios. No entanto, segundo Heber e Silva (2014), a norma institui atribuições distintas e complementares às diferentes esferas de gestão, trazendo grandes desafios e gerando grandes gargalos. Os pesquisadores destacam que a situação se agrava com o distanciamento dos demais entes federados, sobretudo o Estado, para implementação adequada desse importante instrumento de saúde pública e ambiental.

Não obstante, a $\mathrm{CF} / 88$, em seu art. $5^{\circ}, \S 1^{\circ}$, determina que as Leis relacionadas aos direitos fundamentais devam ter pronta efetivação, o que pode ser interpretado como um reforço à boa administração. Para Souza, Hartmann e Silveira (2016), as ações do Judiciário em responsabilizar o Estado, de maneira objetiva e compassiva, são convenientes. Após prospecções, Neves e Pacheco (2018) perceberam que os magistrados não acreditam na capacidade de gestão do poder executivo, ratificando, assim, sua profícua intervenção.

\section{CONSIDERAÇÕES FINAIS}

O objetivo deste estudo foi examinar se a atuação do poder judiciário poderia se tornar um instrumento de efetividade da implementação da Política Nacional de Resíduos Sólidos, ao pressionar a gestão pública por meio de sanções jurídicas, a tornar-se eficiente. Inicialmente, fez-se a análise dos antecedentes evolutivos da administração pública no Brasil o que permitiu a identificação de três modelos distintos, a saber: administração patrimonialista, administração burocrática e administração gerencial. Foi possível concluir que, mesmo com a existência de vestígios de condutas patrimonialistas e de, ainda, serem aplicados mecanismos burocráticos, a administração pública gerencial é o padrão vigente no Brasil contemporâneo, e que o modelo atual demanda diligência para uma gestão orientada para políticas públicas.

Diante disso, foi possível compreender que uma gestão pública eficiente é uma regra indispensável para a cidadania e corresponde a um direito público, mas que carece, sob o enfoque constitucional, de monitoramento sistemático dos procedimentos administrativos. Uma vez que, em sua atuação, o gestor público tem a liberdade para governar amparada pelo poder discricionário, o que exige conduta ética e atenção aos princípios constitucionais da administração pública. Averiguou-se, ainda, que na jurisprudência brasileira não há registros consistentes direcionados 
a atuação do Estado no cumprimento da PNRS.

Percebeu-se, também, que a Política Nacional de Resíduos Sólidos traz direcionamentos para que o Estado possa materializar ações e, assim, possa atender aos direitos fundamentais da população. Desse modo, sua base de sustentação está na responsabilidade compartilhada, por meio da hierarquia de responsabilidades entre os entes federativos. Assim, além de apresentar os instrumentos para sua efetivação, determina, no art. $9^{\circ}$, a ordem de prioridades que devem ser consideradas para a gestão e o gerenciamento de resíduos sólidos.

É fato que a PNRS tramitou quase vinte anos até sua homologação, em 2010. No entanto, pelo que se percebe, os entraves que a retardaram no poder legislativo cruzaram a barreira e se consumaram no executivo, uma vez que o impasse ambiental ainda é um dilema para a sociedade, sobretudo quando, sob justificativa de escassez de recursos, o poder público fecha os olhos para os fundamentos e preceitos constitucionais da boa administração pública, o que muito contribui para que a educação ambiental, vetor para os dois primeiros elementos da prioridade da gestão de resíduos (não geração e redução), não seja uma discussão presente nos currículos escolares e, tão pouco, integre as agendas institucionais.

Nessa perspectiva, entende-se que a implementação das diretrizes instituídas pela PNRS deve ser prioridade para a administração pública contemporânea, uma vez que sua efetividade assegura a solução para esse grave problema ambiental atual.

A partir dos resultados encontrados, considera-se necessária a revisão da Lei n. 9.605/1998, ajustando-a aos preceitos e diretrizes da PNRS, com o intuito de instituir subsídios penais que instiguem a efetividade ambiental de uma gestão pública eficiente ou, como último recurso, subsidiar e fortalecer a atuação do judiciário em suas intervenções para que as administrações municipais se pautem nos princípios constitucionais da administração pública, no cumprimento da legislação e da Constituição, e assim, assegurem um meio ambiente adequado para todos, fatos que exprimem a urgência em tornar essa discussão a pauta central da gestão pública. 


\section{REFERÊNCIAS}

ALMEIDA, R.; SCATENA, L.; LUZ, M. S. Environmental perception and public policies - dichotomy and challenges to the development of a sustainability culture. Ambiente \& Sociedade, São Paulo, v. 20, n. 1, p. 43-64, jan./mar. 2017.

BARDIN, L. Análise de conteúdo. Lisboa: Edições 70, 2009.

BITENCOURT NETO, E. Transformações do Estado e a administração pública no século XXI. Revista de Investigações Constitucionais, Curitiba, v. 4, n. 1, p. 207-225, jan./abr. 2017.

BRASIL. Constituição [1988]. Constituição da República Federativa do Brasil de 1988. Brasília. DF: Presidência da República, Departamento da Casa Civil. Brasília, DF, 1988. Disponível em: http://www.planalto.gov.br/ ccivil_03/Constituicao/Constituicao.htm. Acesso em: 30 out. 2019.

BRASIL. Decreto-lei $n$. 200, de 25 de fevereiro de 1967. Dispõe sobre a organização da Administração Federal [...]. Câmara do Deputados, Brasília, DF, 1967. Disponível em: http://www2.camara.leg.br/legin/fed/declei/1960-1969/decreto-lei-200-25-fevereiro-1967-376033-publicacaooriginal-1-pe.html. Acesso em 30 out. 2019.

BRASIL. Decreto-lei n. 7.404, de 23 de dezembro de 2010. Institui a Política Nacional de Resíduos Sólidos, Presidência da República, Departamento da Casa Civil. Brasília, DF, 2010a. Disponível em: http://www.planalto. gov.br/ccivil_03/_Ato2007-2010/2010/Decreto/D7404.htm. Acesso em 30 out. 2019.

BRASIL. Decreto-lei n. 7.405, de 23 de dezembro de 2010. Institui o Programa Pró-Catador. Presidência da República, Departamento da Casa Civil. Brasília, DF, 2010b. Disponível em: http://www.planalto.gov.br/ ccivil_03/Ato2007-2010/2010/Decreto/D7405.htm. Acesso em 30 out. 2019.

BRASIL. Decreto-lei n. 73.030, de 30 de outubro de 1973. Cria a Secretaria Especial do Meio Ambiente - SEMA. Câmara do Deputados, Brasília, DF, 1973. Disponível em: http://www2.camara.leg.br/legin/fed/decret/1970-1979/decreto-73030-30-outubro-1973-421650-publicacaooriginal-1-pe.html. Acesso em 30 out. 2019.

BRASIL. Lei n. 6.803, de 02 de julho de 1980. Dispõe sobre as diretrizes 
básicas para o zoneamento industrial. Presidência da República, Departamento da Casa Civil. Brasília, DF, 1980. Disponível em: http://www. planalto.gov.br/ccivil_03/LEIS/L6803.htm. Acesso em 30 out. 2019.

BRASIL. Lei n. 6.938, de 31 de agosto de 1981. Institui a Política Nacional do Meio Ambiente. Presidência da República, Departamento da Casa Civil. Brasília, DF, 1981. Disponível em: http://www.planalto.gov.br/ccivil_03/Leis/L6938.htm. Acesso em 30 out. 2019.

BRASIL. Lei n. 7.802, de 11 de julho de 1989. Institui a Lei dos Agrotóxicos. Presidência da República, Departamento da Casa Civil. Brasília, DF, 1989a. Disponível em: http://www.planalto.gov.br/ccivil_03/LEIS/L7802. htm. Acesso em 30 out. 2019.

BRASIL. Lei n. 8.666/93, de 21 de junho de 1993. Regulamenta o art. 37, inciso XXI, da Constituição Federal, institui normas para licitações e contratos da Administração Pública e dá outras providências. Presidência da República, Departamento da Casa Civil. Brasília, DF, 1993. Disponível em: http://www.planalto.gov.br/ccivil_03/leis/18666cons.htm. Acesso em: 30 out. 2020.

BRASIL. Lei $n$. 9.605, de 12 de fevereiro de 1998. Dispõe sobre as sanções penais e administrativas derivadas de condutas e atividades lesivas ao meio ambiente, e dá outras providências. Presidência da República, Departamento da Casa Civil. Brasília, DF, 1998. Disponível em: http://www. planalto.gov.br/ccivil_03/leis/L9605.htm. Acesso em 30 out. 2019.

BRASIL. Lei n. 10.257, de 10 de julho de 2001. Estabelece o Estatuto das Cidades. Presidência da República, Departamento da Casa Civil. Brasília, DF, 2010. Disponível em: http://www.planalto.gov.br/ccivil_03/LEIS/ LEIS_2001/L10257.htm. Acesso em 30 out. 2019.

BRASIL. Lei n. 12.305, de 02 de agosto de 2010. Institui a Política Nacional de Resíduos Sólidos. Presidência da República, Departamento da Casa Civil. Brasília, DF, 2010c. Disponível em: http://www.planalto.gov.br/ccivil_03/_Ato2007-2010/2010/Lei/L12305.htm. Acesso em 30 out. 2019.

BRASIL. Projeto de Lei do Senado n. 354, de 1989. Dispõe sobre o acondicionamento, a coleta, o tratamento, o transporte e a destinação final dos resíduos de serviços de saúde. Senado Federal. Brasília, DF. 1989b. Disponível em: https://www25.senado.leg.br/web/atividade/materias/-/ materia/1711. Acesso em: 29 out. 2020. 
BRASIL. Superior Tribunal de Justiça (2. Turma). Agravo de Instrumento 1.079.392 - SP. Processual Civil e Tributário. Taxa de coleta de lixo domiciliar. Ilegalidade. Agravante: Município de Santo André. Agravado: Eletropaulo Metropolitana Eletricidade de São Paulo S/A. Relatora: Ministra Eliana Calmon, 28 de novembro de 2008. Disponível em: https://ww2. stj.jus.br/processo/revista/documento/mediado/?componente $=\mathrm{MON} \&$ sequencial $=4474053 \&$ num_registro $=200801575655 \&$ data $=20081205$. Acesso em 30 out. 2019.

BRASIL. Supremo Tribunal Federal (2. Turma). Agravo Regimental no Recurso Especial 1.115.373 - PR. Processual Civil e Tributário. Inexistência de violação do art. 557 do CPC. Taxa de coleta de lixo domiciliar. Especificidade e divisibilidade. Ilegalidade. Precedente. Agravante: município de Londrina. Agravado: Antonio Carlos Bertin e outros. Relator: Ministro Humberto Martins, 22 de setembro de 2009. Disponível em: https://ww2. stj.jus.br/processo/revista/documento/mediado/?componente $=$ ATC\&sequencial $=6406534 \&$ num_registro $=200900037635 \&$ data $=20091014 \&$ tipo $=5 \&$ formato=PDF. Acesso em: 30 out. 2019.

BRASIL. Superior Tribunal de Justiça (2. Turma). Recurso Especial 1199572-MG. Recurso especial. Embargos de declaração. Interrupção. Prazo Recursal. Exceção. Intempestividade. Prequestionamento. Ausência. Súmula 211/stj. Violação direta à constituição federal. Não-cabimento. Notificação. Edital. Excepcionalidade. Domicílio incerto. Não sabido. Recorrente: Município de Belo Horizonte Recorrido: Estado de Minas Gerais Relator: Min. Castro Meira, 22 de setembro de 2010d. Disponível em: https://ww2.stj.jus.br/processo/revista/documento/mediado/?componente $=$ ITA\&sequencial $=1001570 \&$ num_registro $=201001185233 \& d a-$ ta $=20100922 \&$ formato $=P D F$. Acesso em: 30 out. 2019.

BRASIL. Superior Tribunal de Justiça (3. Turma). Agravo em Recurso Especial 290114-MG. Processual Civil. Agravo em Recurso Especial. Suposta ofensa ao art. 535 do CPC. Inexistência de vício no Acórdão recorrido. Tributário. Taxa de coleta de lixo. Entrega da guia de recolhimento. Notificação do lançamento. Especial eficácia vinculativa do acórdão proferido no Resp. n. 1.111.124/PR. Representativo de controvérsia. Ônus probatório do contribuinte. Agravo não provido. Agravante: Clube Atlético Mineiro. Agravado: Município de Belo Horizonte. Relator: Min. Mauro Campbell Marques, 31 de maio de 2013. Disponível em: https://ww2.stj.jus. $\mathrm{br} /$ processo/revista/documento/mediado/?componente=MON\&sequen- 
cial $=29086822 \&$ num_registro $=201300227465 \&$ data $=20130610$. Acesso em: 30 out. 2019.

BRASIL. Superior Tribunal de Justiça (2. Turma). Agravo em Recurso Especial 666209 - PR. Agravante: Goodyear do Brasil Produtos de Borracha LTDA. Agravado: Ministério Público do Estado do Paraná. Relatora: Ministra Assusete Magalhães, 17 de março de 2015. Disponível em: https://ww2.stj.jus.br/processo/revista/documento/mediado/?componente $=$ MON\&sequencial $=45592402 \&$ num_registro $=201500389999 \& d a-$ $\mathrm{ta}=20150406$. Acesso em: 30 out. 2019.

BRASIL. Superior Tribunal de Justiça (2. Turma). Agravo em Recurso Especial 813.166 - PR. Administrativo e Processual Civil. Ausência de Prequestionamento. Súmulas 282 e 356 do STF. Razões Recursais Dissociadas da Fundamentação do Acórdão Recorrido. Incidência das Súmulas 283 e 284 do STF. Agravo conhecido para negar seguimento ao recurso especial. Agravante: Abilux - Associação Brasileira da Indústria de Iluminação. Agravado: Ministério Público do Estado do Paraná. Relator: Ministro Humberto Martins, 03 de fevereiro de 2016. Disponível em: https://ww2. stj.jus.br/processo/revista/documento/mediado/?componente $=\mathrm{MON} \&-$ sequencial $=57054637 \&$ num_registro $=201502760002 \&$ data $=20160210$. Acesso em 30 out. 2019.

BRASIL. Superior Tribunal de Justiça (2. Turma). Recurso Especial 1698749 - RS. Processual Civil. Recurso Especial. Enunciado administrativo n. 3/STJ. Improbidade administrativa. Licitação e contrato administrativo. Serviço de transporte escolar. Imputação de fraude. Direcionamento da licitação. Superdimensionamento do objeto do certame. Ausência de fiscalização do contrato. Conduta improba configurada a partir dos elementos fáticos e probatórios constantes dos autos. Súmula 7/STJ. Recurso especial não conhecido. Recorrentes: Transportes JC Lopes Eireli, José Claudio Lopes, Urban Serviços e Transportes Ltda, Claudia Daiane Lopes, Marcos da Rosa Lopes, João Carlos Brum. Recorrido: Ministério Público do Estado do Rio Grande do Sul. Relator: Ministro Mauro Campbell Marques, 11 de dezembro de 2017. Disponível em: https://ww2.stj.jus. $\mathrm{br} / \mathrm{processo} / \mathrm{revista} /$ documento/mediado/?componente $=$ MON\&sequencial $=79258849 \&$ num_registro $=201701165169 \&$ data $=20171214 \&$ tipo $=0$. Acesso em 30 out. 2019. 
BRASIL. Supremo Tribunal Federal (2. Turma). Agravo Interno no Agravo em Recurso Especial 1.190.179 - SP. Administrativo e Processual Civil. Agravo Interno no Agravo em Recurso Especial. Improbidade administrativa. Acórdão que, em face dos elementos de prova dos autos, concluiu pela ausência de comprovação do elemento subjetivo e pela não configuração de ato de improbidade administrativa. Súmula 7/STJ. Agravo interno improvido. Agravante: Ministério Público Federal. Agravado: Atria Construtora LTDA. Relatora: Ministra Assusete Magalhães, 15 de maio de 2018a. Disponível em: https://ww2.stj.jus.br/processo/revista/documento/mediado/?componente $=$ ITA\&sequencial $=1712621 \&$ num_registro $=201702594276 \&$ data $=20180521 \&$ formato $=$ PDF. Acesso em 30 out. 2019.

BRASIL. Superior Tribunal de Justiça (2. Turma). Agravo em Recurso Especial 1.251.315 - SP. Agravante: Ministério Público do Estado de São Paulo. Agravado: Município de Caiuá. Relator: Ministro Francisco Falcão, 13 de junho de 2018b. Disponível em: https://ww2.stj.jus.br/processo/revista/ documento $/$ mediado $/$ componente $=$ MON\&sequencial $=84527475 \&$ num registro $=201800382992 \&$ data $=20180621$. Acesso em 30 out. 2019.

BRASIL. Superior Tribunal de Justiça. Suspensão de Segurança 3.093 - AL. Requerente: Município de Maceió. Requerido: Tribunal de Justiça do Estado de Alagoas. Relator: Ministro Presidente do STJ (João Otávio de Noronha), 30 de maio de 2019. Disponível em: https://ww2.stj.jus. $\mathrm{br} / \mathrm{processo} / \mathrm{revista} /$ documento/mediado/?componente=MON\&sequencial $=96113330 \&$ num_registro $=201901453096 \&$ data $=20190603 \&$ tipo $=0$. Acesso em: 30 out. 2019.

BRULON, V.; OHAYON, P.; ROSENBERG, G. A reforma gerencial brasileira em questão: contribuições para um projeto em construção. Revista do Serviço Público - RSP, Brasília, DF, v. 63, n. 3, p. 265-284, jul./set. 2012.

CÂMARA, J. B. D. Governança ambiental no Brasil: ecos do passado. Revista de Sociologia e Política, Curitiba, v. 21, n. 46, p. 125-146, jun. 2013.

CEZAR, L. C. Reflexões sobre a comunicação em políticas públicas: proposta de um modelo de avaliação da comunicação governamental. Revista de Administração Pública, Rio de Janeiro, v. 52, n. 1, p. 52-70, jan./fev. 2018.

COMPARATO, F. K. Resta ainda, porventura, alguma esperança? Estudos Avançados, São Paulo, v. 32, n. 92, p. 31-45, jan./abr. 2018. 
CORRALO, G. S. Boa governança municipal. In: MACHADO, E. D.; FREITAS, R. S.; TAVARES, A. A. (Orgs.). Direitos Fundamentais e Democracia V. v. 1. Florianópolis: Conpedi, 2014. p. 398-421. Disponível em: http://publicadireito.com.br/publicacao/ufpb/livro.php?gt=236. Acesso em: 30 out. 2019.

CORRALO, G. S. Há um direito fundamental à boa governança? Espaço Jurídico: Journal of Law, Chapecó, v. 18, n. 1, p. 165-184, 2017.

CORREIA, J. M. S. Os grandes traços do direito administrativo no século XXI. A\&C-Revista de Direito Administrativo \& Constitucional, Belo Horizonte, v. 16, n. 63, p. 45-66, jan./mar. 2016.

COSTA, F. L.; COSTA, E. M. L. Nova história da administração pública brasileira: pressupostos teóricos e fontes alternativas. Revista de Administração Pública, Rio de Janeiro, v. 50, n. 2, p. 215-236, mar./abr. 2016.

CUNHA, C. G. S. Avaliação de políticas públicas e programas governamentais: tendências recentes e experiências no Brasil. Revista Estudos de Planejamento, Porto Alegre, n. 12, p. 27-57, dez. 2018.

FARIA, C. R. S. M. A Política Nacional de Resíduos Sólidos. Boletim do Legislativo, Brasília, DF, n. 15, jun. 2012. Disponível em https://www2. senado.leg.br/bdsf/bitstream/handle/id/242672/Boletim2012.15.pdf?sequence $=1$. Acesso em 30 out. 2019.

FREITAS, J. Reflexões sobre moralidade e direito administrativo. Revista do Direito, Santa Cruz do Sul, n. 29, p. 94-115, jan./jun. 2008.

GICO JUNIOR, I. T. O princípio da eficiência na jurisprudência do STF. Revista de Direito Administrativo, Rio de Janeiro, v. 277, n. 2, p. 107-148, maio/ago. 2018.

GRINOVER, A. P. O controle das políticas públicas pelo Poder Judiciário. Revista do Curso de Direito, v. 7, n. 7, p. 9-37, 2010.

HACHEM, D. W. A noção constitucional de desenvolvimento para além do viés econômico-Reflexos sobre algumas tendências do Direito Público brasileiro. A\&C-Revista de Direito Administrativo \& Constitucional, Belo Horizonte, v. 13, n. 53, p. 133-168, jul./set. 2013.

HEBER, F.; SILVA, E. M. Institucionalização da política nacional de resíduos sólidos: Dilemas e constrangimentos na região metropolitana de Aracaju (SE). Revista de Administração Pública-RAP, v. 48, n. 4, p. 913$-937,2014$. 
JAPIASSÚ, C. E.; GUERRA, I. F. 30 anos do relatório Brundtland: nosso futuro comum e o desenvolvimento sustentável como diretriz constitucional brasileira. Revista de Direito da Cidade, Rio de Janeiro, v. 9, n. 4, p. 1884-1901, out./dez. 2017.

KOHLS, C. C.; LEAL, M. C. H. Boa administração pública e fundamentos constitucionais das políticas públicas na perspectiva do Supremo Tribunal Federal. Revista de Estudos Constitucionais, Hermenêutica e Teoria do Direito, São Leopoldo, v. 7, n. 2, p. 188-196, maio/ago. 2015.

LUNAS, M. C. F. S.; OLIVEIRA, A. K. M.; BONONI, V. L. R. Políticas Públicas de Desenvolvimento: Convergências e Divergências no Geoparque Bodoquena-Pantanal1. Ambiente \& Sociedade, São Paulo, v. 19, n. 3, p. 155-176, jul./set. 2016.

MAIELlO, A.; BRITTO, A. L. N. P.; VALLE, T. F. Implementação da Política Nacional de Resíduos Sólidos. Revista de Administração Pública, Rio de Janeiro, v. 52, n. 1, p. 24-51, jan./fev. 2018.

MARTINS, H. F. Administração para o desenvolvimento: a relevância em busca da disciplina. Estudos de Administração e Sociedade, Niterói, v. 2, n. 2, p. 8-18, maio/ago. 2018 .

NASCIMENTO NETO, P.; MONTEIRO, T. A. Política nacional de resíduos sólidos-reflexões acerca do novo marco regulatório nacional. Revista Brasileira de Ciências Ambientais, São Paulo, 15 ed., p. 10-19, mar. 2010.

NEVES, P. B. P.; PACHECO, M. A. B. Saúde pública e Poder Judiciário: percepções de magistrados no estado do Maranhão. Revista Direito GV, São Paulo, v. 13, n. 3, p. 749-768, 2018.

OHLWEILER, L. P. The constitutional principles of public administration and the practical world in Administrative Law. Revista de Estudos Constitucionais, Hermenêutica e Teoria do Direito, São Leopoldo, v. 5, n. 2, p. 150-168, jul./dez. 2013.

OLIVEIRA, D. M. F. Algumas reflexões sobre o controle judicial da administração pública contemporânea. REI - Revista Estudos Institucionais, Rio de Janeiro, v. 3, n. 1, p. 210-241, 2017.

ONU - ORGANIZAÇÃO DAS NAÇÕES UNIDAS. Declaração do Rio de Janeiro. Estudos Avançados, São Paulo, v. 6, n. 15, p. 153-159, ago. 1992. 
PEREIRA, L. C. B. Uma reforma gerencial da administração pública no Brasil. Revista do Serviço Público, Brasília, DF, v. 49, n. 1, p. 5-42, jan./ mar. 1998.

PEREIRA, M. L. Política da Administração e o Princípio da Moralidade. Coletânea de Julgados e Momentos Jurídicos dos Magistrados no TFR e no STJ, Brasília, DF, n. 44, p. 208-215, 2004. Disponível em: https://ww2.stj. jus.br/publicacaoinstitucional///index.php/coletanea/article/view/355/317. Acesso em: 30 out. 2019.

PEREIRA, R. M. As contratações públicas sustentáveis como incentivo econômico para a produção e o consumo sustentáveis. Revista Jurídica da Procuradoria-Geral do Distrito Federal, Brasília, DF, v. 39, n. 1, p. 55-70, jul./dez. 2014.

PESSOA, F. M. G.; CARDOSO, H. R.; SOUSA, O. A. R. Possibilidade e limites do controle judicial das ações e das omissões da administração pública na implantação de políticas públicas com sede constitucional. $A \& C$ - Revista de Direito Administrativo \& Constitucional, Curitiba, v. 15, n. 61, p. 117-144, 2015.

RIBEIRO FILHO, W. F.; VALADARES, J. L. Governança: uma nova perspectiva de gestão aplicada à administração pública. The Journal of Engineering and Exact Sciences, Viçosa, v. 3, n. 5, p. 0721-0723, 2017.

ROMÃO NETTO, J. V. Estrutura administrativa do governo brasileiro, cultura política e a busca pela sociedade ideal. Sociedade e Estado, Brasília, DF, v. 31, n. 1, p. 211-235, jan./abr. 2016.

SECCHI, L. Modelos organizacionais e reformas da administração pública. Revista de Administração Pública, Rio de Janeiro, v. 43, n. 2, p. 347-369, 2009.

SOUZA, L. R.; HARTMANN, D.; SILVEIRA, T. Dano ambiental e a necessidade de uma atuação proativa da Administração Pública. Veredas do Direito, Belo Horizonte, v. 12, n. 24, p. 343-373, 2016.

TEIXEIRA, A. V. Ativismo judicial: nos limites entre racionalidade jurídica e decisão política. Revista Direito GV, São Paulo, v. 8, n. 1, p. 037-057, 2012 .

VELOSO, J. R. S. O modelo constitucional brasileiro de gestão de resultados como mecanismo de freios e contrapesos para moderar o conflito entre os poderes em benefício do cidadão. Publicações da Escola da AGU, Belo Horizonte, v. 10, n. 4, p. 39-54, 2018. 
ŽURGA, G. In search of sustainable public administration: what should, could, or must be done. Romanian Journal of Political Science, Bucharest, v. 17, n. 2, general issue - winter 2017.

Artigo recebido em: 31/10/2019. Artigo aceito em: 28/10/2020.

\section{Como citar este artigo (ABNT):}

BEZERRA, A. N. L.; ROCHA, P. H. F.; MOITA NETO, J. M. Resíduos sólidos: a má gestão pública como problema ambiental. Veredas do Direito, Belo Horizonte, v. 17, n. 39, p. 39-66, set./dez. 2020. Disponível em: http:// www.domhelder.edu.br/revista/index.php/veredas/article/view/1694. Acesso em: dia mês. ano. 